Supporting Information

\title{
Mussel-Inspired Self-Healing Metallopolymers for Silicon Nanoparticle Anodes
}

You Kyeong Jeong广 and Jang Wook Choi ${ }^{* \dagger}$

†School of Chemical and Biological Engineering and Institute of Chemical Processes, Seoul

National University, 1 Gwanak-ro, Gwanak-gu, Seoul 08826, Republic of Korea.

*E-mail: jangwookchoi@snu.ac.kr (J.W.C.). 


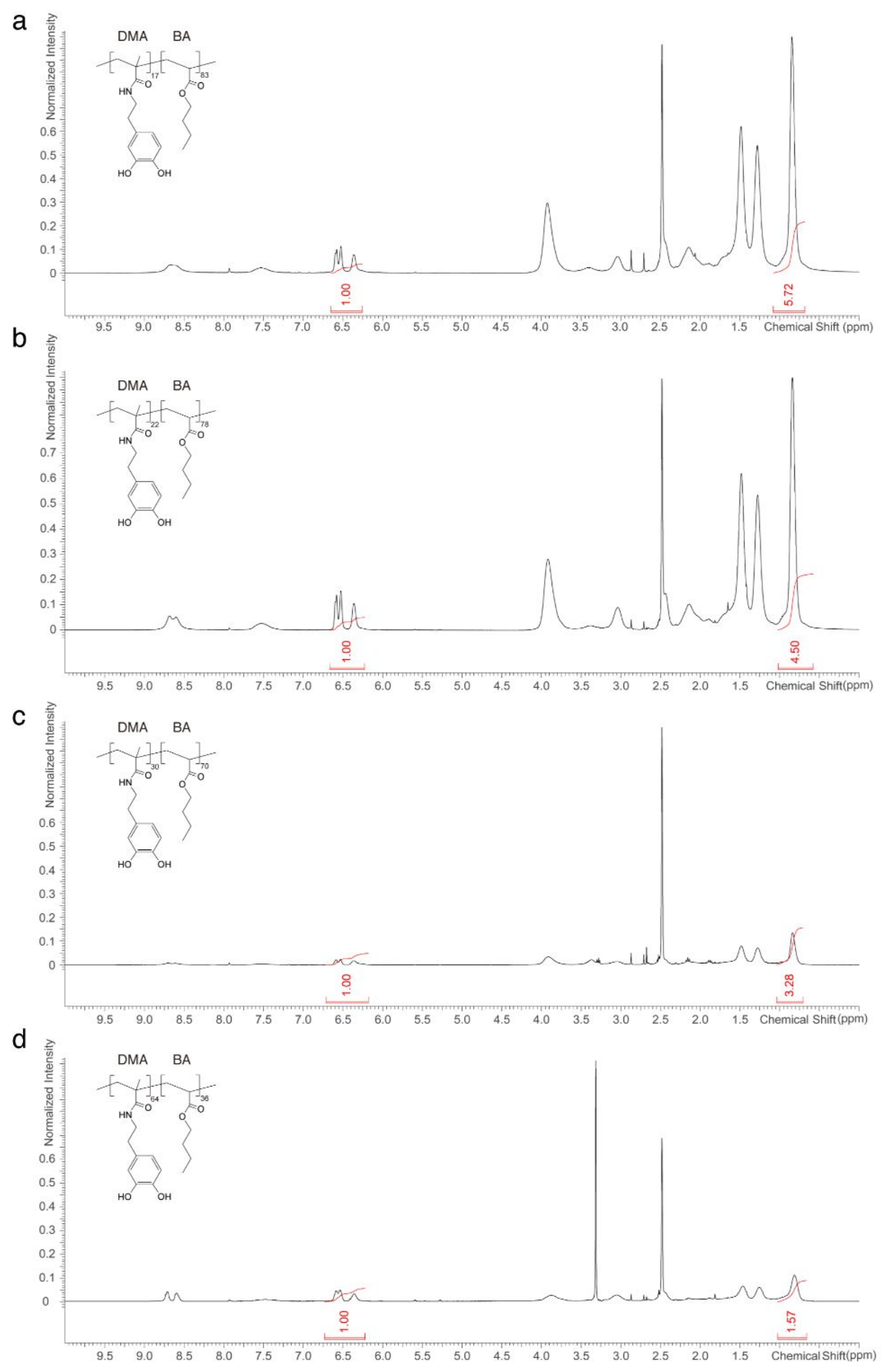

Figure S1. ${ }^{1} \mathrm{H}-\mathrm{NMR}$ spectra of poly $\left(\mathrm{DMA}_{x}-\mathrm{BA}_{y}\right)$ derivatives. a) poly $\left(\mathrm{DMA}_{17}-\mathrm{BA}_{83}\right)$ b) $\left.\left.\operatorname{poly}\left(\mathrm{DMA}_{22}-\mathrm{BA}_{78}\right) \mathrm{c}\right) \operatorname{poly}\left(\mathrm{DMA}_{30}-\mathrm{BA}_{70}\right) \mathrm{d}\right) \operatorname{poly}\left(\mathrm{DMA}_{64}-\mathrm{BA}_{36}\right)$. 

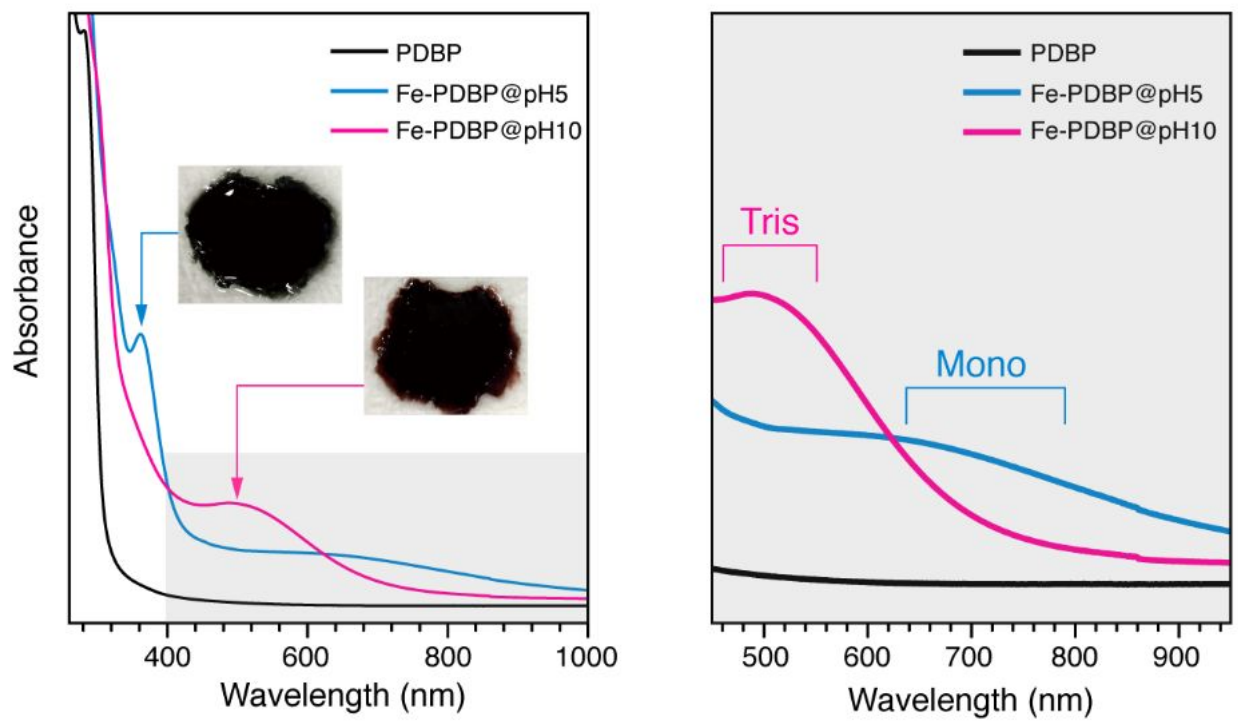

Figure S2. UV-vis spectra of different polymer films. UV-vis spectra of PDBP (black), FePDBP@pH5 (blue), and Fe-PDBP@pH10 (magenta). Enlarged version (right) indicating the Fe ${ }^{3+}$ (tris)catechol complex (magenta) of Fe-PDBP@pH10 and the $\mathrm{Fe}^{3+}$-(mono)catechol complex (blue) of Fe-PDBP@pH5.

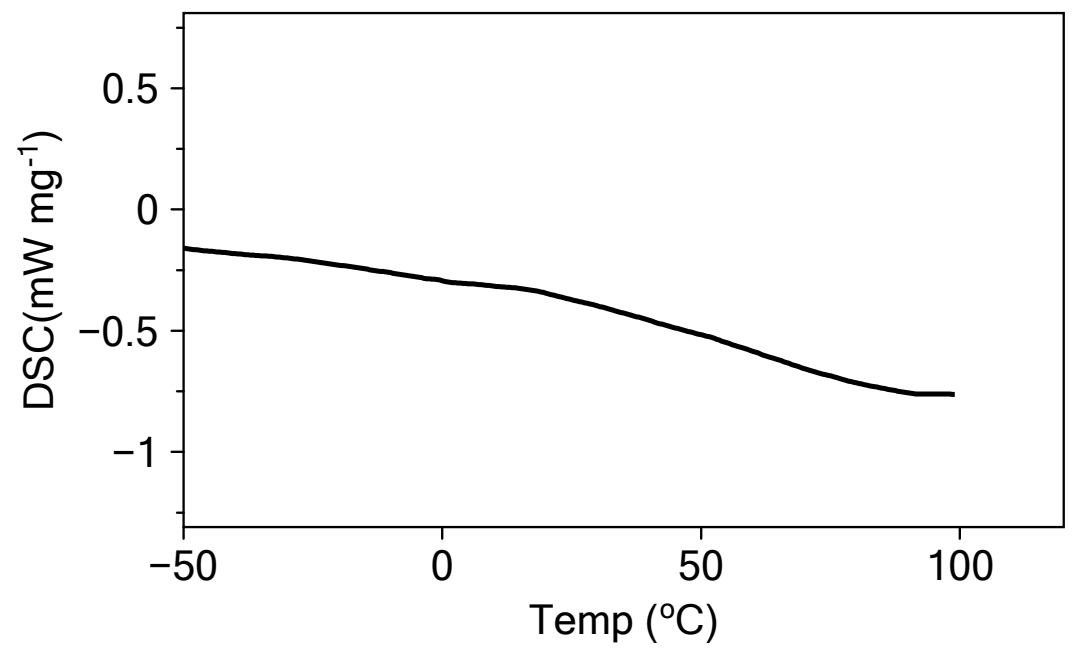

Figure S3. Differential scanning calorimetry profile of $\mathrm{PDMA}_{100}$. 


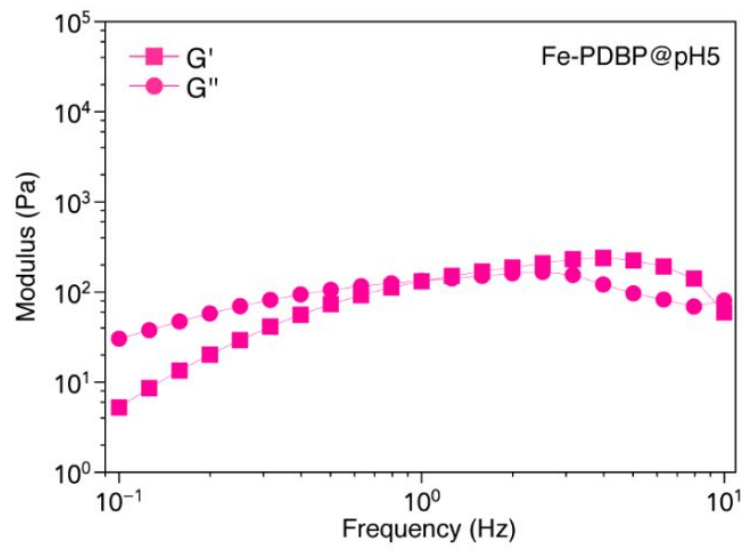

Figure S4. Rheology profiles of Fe-PDBP@pH5 in the frequency range $10^{-1}-10^{1} \mathrm{~Hz}$ when measured under a constant stress of $100 \mathrm{~Pa}$ (G': elastic moduli, G': viscous moduli).

a

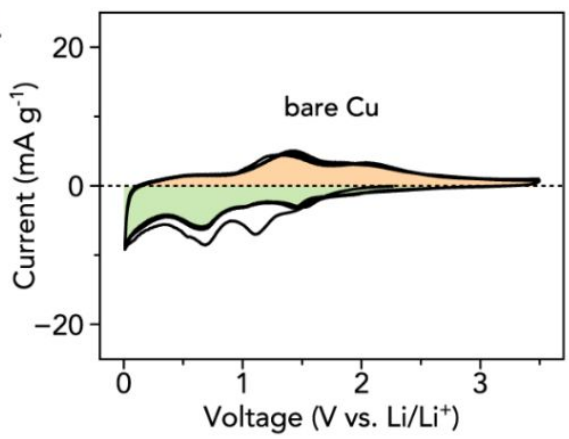

C

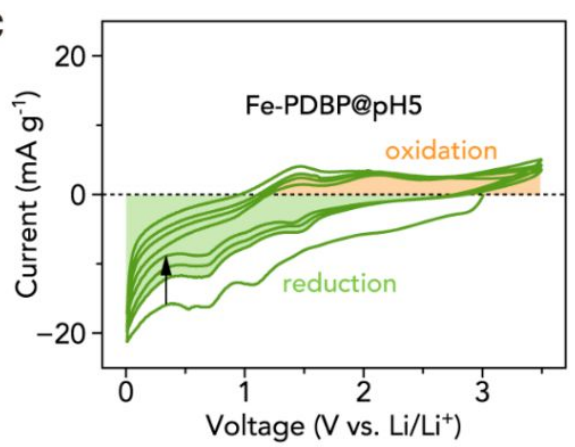

b
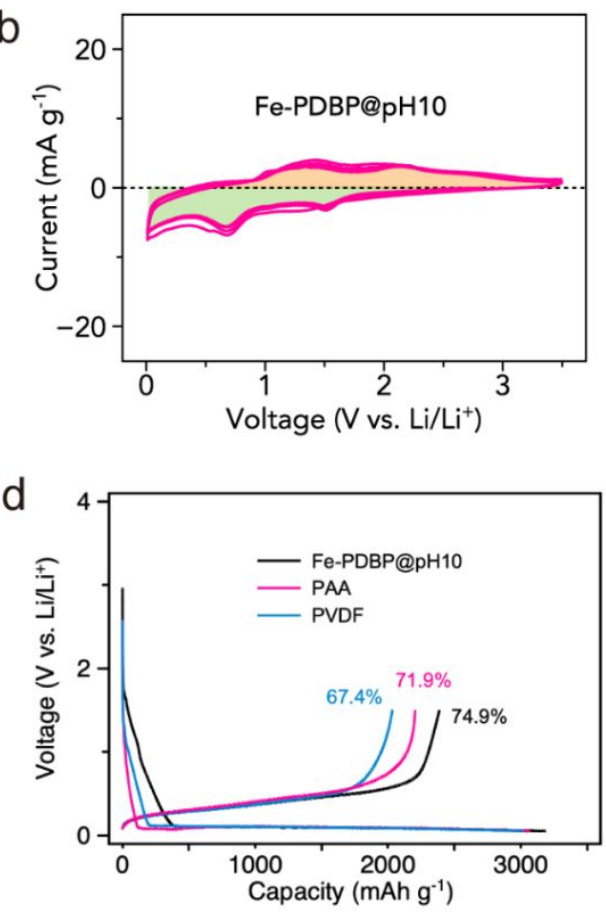

Figure S5. Cyclic voltammetry of (a) bare Cu, (b) Fe-PDBP@pH10 coated Cu, and (c) FePDBP@pH5 coated Cu foils in the potential range of $0.01-3.5 \mathrm{~V} v s \mathrm{Li} / \mathrm{Li}^{+}$in the electrolyte with 1 $\mathrm{M}$ of lithium hexafluorophophate $\left(\mathrm{LiPF}_{6}\right)$ in 1:1 volume ratio of ethylene carbonate $(\mathrm{EC})$ and dimethyl carbonate (DMC) with $10 \mathrm{v} \%$ of fluoroethylene carbonate (FEC). (d) The voltage profiles in the first cycles of the Si electrodes based on different binders. C-rate $=0.1 \mathrm{C}$. 